\title{
Millennium development holes
}

\author{
The political commitment to helping the developing world is failing to deliver on its promises. The problem \\ is made worse by the questionable evaluation of progress.
}

$\mathrm{n} 2000,189$ world leaders committed to eight Millennium Devel-
opment Goals (MDGs), ranging from halving extreme poverty and
hunger, and rolling back killer diseases such as AIDS and malaria, to providing universal primary education. The deadline of 2015 to achieve all these ambitious goals is now rapidly approaching.

As a rallying cry that has pushed development up the international political agenda, the goals have been an indisputable success. They have also, for better or worse, conferred power and legitimacy on interests within the international aid machine, in particular the United Nations (UN) and the World Bank.

But the goals are ultimately political promises, and as such they are fickle. As the economist Jeffrey Sachs pointed out at last week's 'BioVision' meeting in Lyon, France, the G8 leaders promised in 2005 to double aid to Africa from US\$25 billion in 2004 to at least $\$ 50$ billion in 2010. But African countries still have no idea how or when aid levels will increase. Creative accounting means that supposed new aid is sometimes just a repackaging of existing aid or a debt cancellation. What aid has emerged has not led to the organized, massive expansion of investments in clinics, schools, agriculture and infrastructure that is needed.

This bad situation is made even worse by the pseudoscientific veneer conferred by evaluating progress on the MDGs using 48 quantitative indicators compared with a 1990 baseline. Every year, the UN rolls out reports with slick graphics, seemingly noting with precise scientific precision progress towards the goals. But the reports mask the fact that the quality of most of the underlying data sets is far from adequate. Moreover, the indicators often combine very different types of data, making aggregation and analysis of the deficient data even more complicated.

There are decent data for just a handful of indicators, such as child mortality, but for most of the 163 developing countries, many indicators do not even have two data points for the period 1990-2006. And few developing countries have any data for around 1990, the baseline year. It is impossible to estimate progress for most of the indicators over less than five years, and sparse poverty data can only be reliably compared over decades. To pretend that progress towards the 2015 goals can be accurately and continually measured is false.

Significant efforts are now being made to improve data collection. Meanwhile, UN agencies fill in the missing data points using 'modelling' - in practice, a recipe for potentially misleading extrapolation and political tampering.

Indeed, the lack of data makes it impossible not only to track progress, but also to assess the effectiveness of measures taken. Has the existence of the MDGs changed pre-existing trends? Are bednets helping to control malaria? Are improvements in Asia down to the MDGs or simply economic growth? Currently, it's impossible to tell. Meanwhile, spurious claims of achievement are promoted.

Funding the scientific evaluation of interventions would pay dividends in enabling rigorous project management. But although billions of dollars are now flowing into aid and disease control, researchers complain that they struggle to get even tiny funds for evidence-based research to assess which "A lack of data makes it impossible not only to track progress, but also to assess the effectiveness of measures taken." interventions work. "If I want 10 tonnes of DDT it's no problem; if I want $\$ 10,000$ to see if the 10 tonnes made any difference, forget it," says one malaria researcher.

It is important to take action towards the goals rather than use the lack of reliable information as an excuse for inaction. But investment in an evidence-based approach to aid interventions, assessed independently of the UN, is also essential. Otherwise, in 2015, the MDGs could be buried in history's graveyard alongside other wellintentioned but failed development efforts.

\section{Independence day?}

Spain has increased science funding but now needs to modernize the organizations at the top.

'N ew government pledges to double research budget.' How often have scientists heard this type of promise and been disappointed? All the more credit, then, to Spain's politicians, who have delivered on it. When the socialist government swept to power in March 2004, it launched a multifaceted programme called Ingenio 2010, founded on a commitment to raise the country's spending on research from $1.1 \%$ of its GDP - well below the European Union average of $1.8 \%$ - to $2 \%$ by 2010 . The civilian research budget has already more than doubled.

Given equivalent budgets, would Spain's researchers be able to deliver the same quality as the big European players? Some of Spain's élite research institutes, such as the CNIO, the national cancer centre in Madrid, already do so. But broader success will depend on Spain's plans to modernize its science management. If the money is to be well spent, the new basic-research agencies currently being created must adopt European Union norms. In particular, they must be free of direct political interference - a point of contention among some government bureaucrats.

Researchers say the new money is already making a palpable difference. The number of research positions, the acceptance rate of grants, and grant sizes have all increased. There are more diverse sources of grants, thanks to strategic programmes opened up within 